\title{
GROWTH OF POLYNOMIALS WITH PRESCRIBED ZEROS
}

\author{
K. K. DeWAn And ARTy Ahuja
}

Abstract. In this paper, we study the growth of polynomials of degree $\mathrm{n}$ having all its zeros on $|z|=k, k \leqslant 1$. Using the notation $M(p, t)=\max _{|z|=t}|p(z)|$, we measure the growth of $p$ by estimating $\left\{\frac{M(p, t)}{M(p, 1)}\right\}^{s}$ from above for any $t \geqslant 1, s$ being an arbitrary positive integer.

Mathematics subject classification (2010): 30A10, 30C10, 30C15.

Keywords and phrases: Polynomials, maximum modulus, zeros, extremal problems.

\section{REFERENCES}

[1] N. C. Ankeny and T. J. Rivlin, On a Theorem of S. Bernstein, Pacific J. Math., 5 (1955), 849-852.

[2] K. K. Dewan And A. Mir, Note on a Theorem of S. Bernstein, Southeast Asian Bulletin of Math., 31 (2007), 691-695.

[3] N. K. Govil, On the Theorem of S. Bernstein, J. Math. and Phy. Sci., 14 (1980), 183-187.

[4] G. PÓlya AND G. SZEgÖ, Aufgaben and Lehrsatze aus der Analysis, Springer-Verlag, Berlin, 1925.

[5] M. A. QAZI, On the maximum modulus of polynomials, Proc. Amer. Math. Soc., 115 (1992), 337-343.

[6] W. M. ShaH, Extremal Properties and Bounds for the Zeros of Polynomials, Ph. D. Thesis, University of Kashmir, 1998. 